\title{
PERBEDAAN PERILAKU KEKERASAN SEBELUM DAN SESUDAH TERAPI RELAKSASI NAFAS DALAM PADA PASIEN PERILAKU KEKERASAN
}

\author{
Differences Of Violence Behavior Before And After Breathing Relaxation Therapy In Violence \\ Behavior Patients
}

Roufuddin $^{1}$ Mutiatun Hoiriyah ${ }^{2}$

${ }^{1}$ STIKES Artha Bodhi Iswara Surabaya

${ }^{2}$ STIKES Insan Se Agung Bangkalan

\author{
Alamat Korespondensi : Prodi Keperawatan STIKES ABI \\ Jl. Pumpungan III No. 29 Sukolilo Surabaya
}

\begin{abstract}
ABSTRAK
Perilaku kekerasan merupakansalah satu contoh gangguan jiwayang sering terjadi di kehidupanmasyarakat. Tujuan penelitian ini untuk menganalisis perbedaan perilaku kekerasan sebelum dan sesudah terapi relaksasi nafas dalam pada pasien perilaku kekerasan.

Metode penelitian ini menggunakan One Group Pretest - Postest Design. Populasi dalam penelitian ini adalah 32 pasien perilaku kekerasan di ruang Kenari dan sampel dalam penelitian ini sebanyak 30 pasien perilaku kekerasan yang diperoleh menurut kriteria inklusi. Teknik pengambilan sampel diambil menggunakan Consecutive Sampling. Instrumen dalam penelitian ini adalah observasi RUFA. Data dianalisis menggunakan uji statistik Wilcoxon Signed Rank Testdengan nilai signifikansi $p<\alpha, \alpha=0,05$.

Dari hasil penelitian sebelum terapi relaksasi nafas dalam diperoleh kategori perilaku kekerasan sedang $(80 \%)$ dan kategori perilaku kekerasan ringan (20\%). Sesudah terapi relaksasi nafas dalam diperoleh kategori perilaku kekerasan ringan $(83,3 \%)$ dan kategori perilaku kekerasan sedang (16,7\%). Dari hasil uji statistik Wilcoxon Signed Rank Test didapatkan ada perbedaan perilaku kekerasan di Rumah Sakit Jiwa Menur Surabaya dengan nilai kemaknaan $(p=0,000<0,05)$.

Kesimpulannya adalah ada perbedaan perilaku kekerasan sebelum dan sesudah terapi relaksasi nafas dalam pada pasien perilaku kekerasan. Maka dengan ini terbukti adanya penurunan perilaku kekerasan sesudah diberikan terapi relaksasi nafas dalam.
\end{abstract}

Kata Kunci : Relaksasi Nafas Dalam, Pasien Perilaku Kekerasan

\section{ABSTRACT}

Violent behavior is one example of mental disorders that often occur in public life. The purpose of this study was to analyze differences in violent behavior before and after Breathing Relaxation Therapy In Violence Behavior Patients.

This research method used One Group Pretest - Postest Design. The population in this study were 32 patients of violent behavior in Kenari iroom and the samples in this study were 30 patients of violent behavior obtained according to the inclusion criteria. The sampling technique was taken using Consecutive Sampling. Instrument in this research is RUFA observation. Data were analyzed using Wilcoxon Signed Rank Test with significance value $p<\alpha, \alpha=0,05$.

From the results of the study before the deep breathing relaxation obtained medium violent behavior category (80\%) and light violent behavior category (20\%). After deep breathing relaxation therapy obtained light violent behavior categories $(83,3 \%)$ and medium violent behavior category $(16,7 \%)$. The statistic result of Wilcoxon Signed Rank Test shows that there is a difference of violent behavior in Mental Hospital of Menur Surabaya with significance value $(p=0,000<0,05)$.

The conclusion was that there are diffrences in violent behavior before and after deep breathing therapy in patients of violent behavior. Then this proved to be a decrease in violent behavior after being given deep breath relaxation therapy.

Keywords: Deep Breathing Relaxation, Patient of Violent Behavior 


\section{PENDAHULUAN}

Kesehatan jiwa merupakan salah satu dari empat masalah kesehatan utama di negara-negara maju.Meskipun masalah kesehatan jiwa tidak dianggap sebagai gangguan yang menyebabkan kematian secara langsung. Namun gangguan tersebut dapat menimbulkan ketidakmampuan individu dalam berkarya serta ketidaktepatan individu dalam berperilaku yang dapat mengganggu kelompok dan masyarakat serta dapat menghambat pembangunan karena mereka tidak produktif (Videbeck, 2008).

Perilaku kekerasan merupakan keadaan dimana seseorang melakukan tindakan yang membahayakan secara fisik, baik kepada diri sendiri, maupun orang lain. ${ }^{(2)} \mathrm{Hal}$ tersebut dilakukan untuk mengungkapkan perasaan kesal atau marah yang tidak konstruktif. ${ }^{(2)}$ Perilaku kekerasan/amuk dapat disebabkan karena frustasi, takut, manipulasi atau intimidasi.

Negara Indonesia khususnya Propinsi Jawa Tengah prevelensi gangguan jiwa mengalami peningkatan mulai tahun 2005 sampai tahun 2010 (Profil Kesehatan Propinsi Jawa Tengah, 2005-2010). Hal ini menunjukkan bahwa gangguan jiwa termasuk gangguan kesehatan yang perlu mendapat perhatian dari pemerintah maupun masyarakat (Yuhanda, 2013)

Berdasarkan data yang diperoleh pada tanggal 18 November 2016 di Rumah Sakit Jiwa Menur Surabaya didapatkan data total jumlah pasien dari bulan Januari - Agustus 2016 sebanyak 1.679 pasien yaitu perilaku kekerasan $15 \%$, halusinasi $30 \%$, isolasi sosial
$50 \%$, harga diri rendah $12 \%$, defisit perawatan diri $10 \%$, waham $7 \%$, dan bunuh diri $1 \%$. Dari hasil data total jumlah estimasi pasien perilaku kekerasan selama 1 bulan adalah jumlah total pasien yang dirawat sebanyak 210 pasien dan jumlah pasien perilaku kekerasan sebanyak 32 pasien.

Salah satu gejala gangguan jiwa adalah munculnya perilaku yang tidak wajar dari biasanya seperti perilaku kekerasan atau tindakan kekerasan yang tidak wajar. "Kekerasan" juga berkonotasi kecenderungan agresif untuk melakukan perilaku yang merusak. Tindak kekerasan / perilaku kekerasan menimbulkan dampak fisik, psikologis, sosial, serta spiritual bagi korban dan juga mempengaruhi sistem keluarga serta masyarakat menyeluruh (Hamid, 2008).

Dan banyak faktor yang mempengaruhi seseorang mengalami gangguan jiwa. Hingga saat ini diyakini terdapat tiga faktor utama sebagai penyebabnya. Pertama, faktor organobiologi seperti faktor keturunan (genetik), adanya 2 ketidakseimbangan zat-zat neurokimia di dalam otak. Kedua, faktor psikologis seperti adanya mood yang labil, rasa cemas berlebihan, gangguan persepsi yang ditangkap oleh panca indera kita (halusinasi). Dan yang ketiga adalah faktor lingkungan (sosial) baik itu di lingkungan terdekat kita (keluarga) maupun yang ada diluar lingkungan keluarga seperti lingkungan kerja atau sekolah. Dan penyebab perilaku kekerasan lainnya yaitu karena frustasi, takut, manipulasi atau intimidasi. 
Terapi yang dapat dilakukan pada pasien perilaku kekerasan diantaranya adalah terapi relaksasi. Oleh karena itu peneliti melakukan penelitian pada pasien perilaku kekerasan dengan memberikan terapi relaksasi nafas dalam.

\section{METODE PENELITIAN}

Dalam penelitian ini, peneliti menggunakan jenis penelitian pra eksperiment design tanpa kelompok pembanding (Rancangan Pra-eksperimental) tipe one grouppretest - posttest design. Yaitu desain Experimental yang dilakukan pretest sebelum diberikan perlakuan dan posttest setelah dilakukan perlakuan. Kelompok sampel diobservasi mengenai tingkat perilaku kekerasan sebelum dilakukan intervensi, kemudian sampel diberikan perlakuan terapi relaksasi nafas dalam dan setelah itu diobservasi kembali mengenai tingkat perilaku kekerasan (Nursalam, 2013).

Populasi dalam penelitian ini menggunakan populasi estimasi yang diperoleh dari jumlah rata-rata pasien perilaku kekerasan selama 1 bulan terakhir yang dirawat di Ruang Kenari Rumah Sakit Jiwa Menur Surabaya pada bulan Agustus 2016 sebanyak 32 pasien perilaku kekerasan. Dengan sampel sebesar 30 responden.

Variabel independen dalam penelitian ini yaitu terapi relaksasi nafas dalam dan variabel dependen yaitu pasien perilaku kekerasan. Penelitian ini menggunakan instrumen berupa observasi RUFA. Sebelum dilakukan intervensi, diawali dengan mengobservasi menggunakan observasi RUFA sebagai data pre kemudian dilakukan intervensi dan langsung di lakukan observasi post. Analisis statistik diperoleh dengan perangkat komputer menggunakan uji statistik Wilcoxon dengan derajat kemaknaan $\mathrm{p}<0,05$.

\section{HASIL DAN PEMBAHASAN}

Penelitian ini dilakukan selama satu minggu dimulai tanggal 05 Juni 2016 sampai 09 Juni 2017 di Rumah Sakit Jiwa Menur Surabaya. Dari hasil penelitian didapatkan hasil sebagai berikut :

1. Data Umum

Tabel 1. Distribusi Frekuensi Umur Menurut Depkes RI (2009)

\begin{tabular}{|c|c|c|}
\hline Umur (tahun) & Frekuensi & $(\%)$ \\
\hline 17-25 tahun & 9 & $30 \%$ \\
\hline $26-35$ tahun & 7 & $23,3 \%$ \\
\hline 36-45 tahun & 8 & $26,7 \%$ \\
\hline 46-55 tahun & 3 & $10 \%$ \\
\hline 56-65 tahun & 3 & $10 \%$ \\
\hline Total & 30 & $100 \%$ \\
\hline
\end{tabular}

Berdasarkan hasil data tabel 1 distribusi frekuensi kategori usia menurut Depkes RI (2009) menunjukkan bahwa sebagian besar mengalami gangguan jiwa perilaku kekerasan yaitu umur 17-25 tahun sebanyak 9 responden $(30 \%)$.

Tabel 2. Distribusi Frekuensi Tingkat Pendidikan Responden Pasien Perilaku Kekerasan di Ruang Kenari

\begin{tabular}{|l|c|l|}
\hline $\begin{array}{l}\text { Tingkat } \\
\text { Pendidikan }\end{array}$ & Frekuensi & $(\mathbf{\%})$ \\
\hline SD & 8 & $26,7 \%$ \\
\hline SMP & 7 & $23,3 \%$ \\
\hline SMA & 14 & $46,7 \%$ \\
\hline S1 & 1 & $3,3 \%$ \\
\hline Total & $\mathbf{3 0}$ & $\mathbf{1 0 0 \%}$ \\
\hline
\end{tabular}

Berdasarkan hasil tabel 2 menunjukkan bahwa terbanyak responden berlatar belakang pendidikan SMA sebanyak 14 responden $(46,7 \%)$. 
Tabel 3. Distribusi Frekuensi Status Perkawinan Responden Pasien Perilaku Kekerasan di Ruang Kenari

\begin{tabular}{|l|c|c|}
\hline $\begin{array}{l}\text { Status } \\
\text { Perkawinan }\end{array}$ & Frekuensi & $\mathbf{( \% )}$ \\
\hline Menikah & 7 & 23,3 \\
\hline Duda/Janda & 1 & 3,3 \\
\hline Cerai & 2 & 6,7 \\
\hline Belum Menikah & 20 & 66,7 \\
\hline Total & $\mathbf{3 0}$ & $\mathbf{1 0 0} \%$ \\
\hline
\end{tabular}

Berdasarkan tabel 3 di atas menunjukkan bahwa sebagian besar responden belum menikah dengan jumlah 20 responden $(66,7 \%)$.

\section{Data Khusus}

$\begin{array}{ll}\text { Tabel 4. } & \text { Distribusi Frekuensi Perilaku } \\ & \text { Kekerasan Sebelum Diberikan } \\ & \text { Terapi Relaksasi Nafas Dalam } \\ & \text { Pada Pasien Perilaku Kekerasan } \\ & \text { di Ruang Kenari }\end{array}$

\begin{tabular}{|l|c|l|}
\hline $\begin{array}{l}\text { Perilaku } \\
\text { Kekerasan }\end{array}$ & Frekuensi & $\mathbf{( \% )}$ \\
\hline Ringan & 6 & $20 \%$ \\
\hline Sedang & 24 & $80 \%$ \\
\hline Total & $\mathbf{3 0}$ & $\mathbf{1 0 0 \%}$ \\
\hline
\end{tabular}

Berdasarkan tabel 4 diatas menunjukkan bahwa perilaku kekerasan sebelum diberikan terapi relaksasi nafas dalam pada pasien perilaku kekerasan sebagian besar responden mengalami perilaku kekerasan dengan kategori sedang sebanyak 24 pasien $(80 \%)$.

Tabel 5. Distribusi Frekuensi Perilaku Kekerasan Sesudah Diberikan Terapi Relaksasi Nafas Dalam Pada Pasien Perilaku Kekerasan di Ruang Kenari

\begin{tabular}{|l|c|l|}
\hline $\begin{array}{l}\text { Perilaku } \\
\text { Kekerasan }\end{array}$ & Frekuensi & $\mathbf{( \% )}$ \\
\hline Ringan & 25 & $83,3 \%$ \\
\hline Sedang & 5 & $16,7 \%$ \\
\hline Total & $\mathbf{3 0}$ & $\mathbf{1 0 0 \%}$ \\
\hline
\end{tabular}

Berdasarkan tabel 5 diatas menunjukkan bahwa perilaku kekerasan sesudah diberikan terapi relaksasi nafas dalam pada pasien perilaku kekerasan sebagian besar responden yang mengalami perilaku kekerasan berkurang dengan kategori ringan menjadi 25 pasien $(83,3 \%)$.

Dari hasil uji Wilcoxon Rank Test diperoleh nilai kemaknaan $p<\alpha \quad(0,000<$ 0,05), maka terdapat penurunan perilaku kekerasan sebelum dan sesudah di berikan intervensi.

\section{PEMBAHASAN}

1.Perilaku Kekerasan Sebelum Diberikan Terapi Relaksasi Nafas Dalam di Ruang Kenari Rumah Sakit Jiwa Menur Surabaya

Berdasarkan hasil penelitian yang dilalukan pada pasien perilaku kekerasan di Ruang Kenari Rumah Sakit Jiwa Menur Surabaya diketahui bahwa sebelum diberikan terapi relaksasi nafas dalam, pasien mengalami perilaku kekerasan dengan kategori sedang yaitu 24 pasien perilaku kekerasan $(80 \%)$.

Perilaku Kekerasan disebabkan karena pasien frustasi, takut, manipulasi atau intimidasi dan emosi yang tidak terkontrol. Perilaku kekerasan yang dimiliki seseorang dapat dipengaruhi oleh beberapa faktor diantaranya faktor keturunan, faktor lingkungan/sosial baik itu dilingkungan terdekat maupun yang ada diluar lingkungan dan faktor psikologis yaitu adanya mood yang labil, rasa cemas berlebihan, gangguan persepsi yang ditangkap oleh panca indra kita. Dan menurut teori biopsikososial juga disebabkan oleh interaksi yang kompleks 
antara faktor biologic, psikologik, dan sosiokultural (Dewi, 209).

Menurut Stuart \& Laraia menyatakan bahwa perilaku adalah hal yang dapat diobservasi, dicatat, diukur, bergerak atau berespon (Sumirta, 2013). Mengubah perilaku dapat dilakukan dengan 3 strategiyaitu menggunakan kekuasaan/ kekuatan / dorongan, pemberian informasi, diskusi partisipan (Videbeck, 2008). Sedangkan Sunaryo menyatakan bahwa perubahan perilaku dipengaruhi oleh beberapa hal yaitu kebutuhan, motivasi, sikap dan kepercayaan. Dari pernyataan diatas dapat diketahui bahwa perilaku dapat dirubah dengan pemberian informasi, diskusi dan motovasi berdasarkan kebutuhan dan keyakinan individu, perubahan tersebut dapat diobservasi atau diukur (Dewi, 2009).

Dari data umum yang kami dapat, hampir setengahnya pasien perilaku kekerasan berpendidikan SMA sebanyak 14 responden (46\%). Hal ini didukung oleh penelitian Retno (2016) yang menyatakan dari 28 responden jenjang pendidikan hampir setengahnya adalah SMA sebanyak 11 orang $(39,4 \%)$.

Berdasarkan tabel 5.4 di atas menunjukkan bahwa sebagian besar responden belum menikah dengan jumlah 20 responden $(66,7 \%)$. Hal ini didukung oleh penelitian (Retno, 2016) yang menyatakan dari 28 responden didapatkan sebagian besar berstatus tidak kawin sebanyak 15 orang $(53,6 \%)$.

Menurut pendapat saya status hubungan mempengaruhi beban emosional seseorang tersebut. Kondisi status yang belum menikah menjadi faktor pendukung dalam tingginya tingkat emosional seseorang dikarenakan tidak adanya peran keluarga terdekat yang dapat menurunkan serta mengontrol tingkat emosional tersebut sehingga perilaku kekerasan dapat dicegah.

Ditinjau dari data umum pada pasien perilaku kekerasan. Peneliti berupaya memberikan solusi yang mampu mengatasi atau menurunkan tingkat emosional seseorang sehingga menekan terjadinya perilaku kekerasan yaitu dengan memberikan terapi relaksaasi nafas dalam. Selain itu untuk mencegah terjadinya perilaku kekerasan maka sebaiknya terapi relaksasi nafas dalam disertai dengan terapi fisik agar perilaku kekerasan tetap stabil dan dapat mengontrol emosinya.

2.Perilaku Kekerasan Sesudah Diberikan Terapi Relaksasi Nafas Dalam di Ruang Kenari Rumah Sakit Jiwa Menur Surabaya

Berdasarkan penelitian di Ruang Kenari Rumah Sakit Jiwa Menur Surabaya sesudah diberikan terapi relaksasi nafas dalam didapatkan berkurangnya perilaku kekerasan dalam kategori ringan yaitu 25 pasien perilaku kekerasan $(83,3 \%)$. Hal ini dibuktikan oleh hasil lembar observasi RUFA yang telah dibagikan sebagai indikator dalam menentukan tingkat terjadinya perilaku kekerasan pada seseorang yang ditandai dengan indikator perilaku mata melotot, dengan intonasi bicara yang tinggi 
disertai ekspresi tegang dengan pandangan tajam.

Pasien perilaku kekerasan yang disebabkan oleh frustasi, takut, manipulasi atau intimidasi, emosi yang tidak terkontrol dan lingkungan sekitarnya yang tidak sesuai dengan keadaan / perasaannya dapat memicu timbulnya tindakan perilaku kekerasan ini. Lingkungan dengan peristiwa-peristiwa yang mencerminkan tindakan kekerasan seperti pembunuhan, kerusuhan, pembakaran, pemukulan, dan penyiksaan dapat menyebabkan perilaku kekerasan meningkat. Pola hidup juga mempengaruhi perilaku kekerasan seperti malas berolahraga dengan tarik nafas maka berisiko tinggi untuk terjadi perilaku kekerasan ini karena tarik nafas berfungsi untuk menurunkan keluhan fisik, memberikan perasaan tenang, mengurangi stress baik stress fisik maupun emosional, serta dapat menurunkan ketegangan dan memberikan ketenangan. Untuk mengurangi perilaku kekerasan maka lakukan relaksasi nafas dalam dengan langkah-langkah sebagai berikut : meletakkan satu tangan di dada dan satu tangan di abdomen, melakukan nafas dalam, merasakan mengembangnya abdomen, menahan nafas hingga 3 hitungan, menghembuskan nafas perlahan dalam 3 hitungan, merasakan mengempisnya abdomen dari kontraksi otot. Dalam penelitian ini terbukti bahwa sesudah melakukan relaksasi nafas dalam tersebut sesuai aturan dapat mengurangi perilaku kekerasan.

Menurut pendapat peneliti, pasien perilaku kekerasan sudah dapat mengatur emosi dan menjaga keseimbangan emosinya dengan cara melakukan terapi relaksasi nafas dalam yang disertai dengan latihan fisik, sehingga emosi tidak berlebihan dan tidak terjadi pada tingkat intensitas yang tinggi.

\section{Perbedaan Perilaku Kekerasan Sebelum} dan Sesudah Diberikan Terapi Relaksasi Nafas Dalam di Ruang Kenari Rumah

\section{Sakit Jiwa Menur Surabaya}

Hasil penelitian menunjukan bahwa dapat disimpulkan ada perbedaan perilaku kekerasan sebelum dan sesudah diberikan terapi nafas dalam. Berdasarkan uji Wilcoxon Rank Test diperoleh nilai kemaknaan $p<\alpha(0,000<0,05)$. Perilaku kekerasan sebelum dilakukan terapi relaksasi nafas dalam pada pasien perilaku kekerasan di Ruang Kenari Rumah Sakit Jiwa Menur Surabaya mengalami perilaku kekerasan dengan kategori sedang $(80 \%)$. Sesudah di lakukan terapi relaksasi nafas dalam pada pasien perilaku kekerasan mengalami penurunan perilaku kekerasan dengan kategori ringan 25 pasien perilaku kekerasan $(83,3 \%)$, dan kategori sedang 5 pasien perilaku kekerasan (16,7\%). Maka H1 diterima artinya ada perbedaan yang bermakna perilaku kekerasan sebelum dan sesudah terapi relaksasi nafas dalam pada pasien perilaku kekerasan di Ruang Kenari Rumah Sakit Jiwa Menur Surabaya.

Menurut penelitian yang dilakukan oleh Kustanti dan Widodo menunjukkan bahwa ada pengaruh terapi relaksasi yang berhubungan dengan pasien perilaku kekerasan salah satunya adalah relaksasi nafas dalam dan penelitian tersebutkan 
mendapatkan hasil bahwa ada pengaruhnya (Kustanti, 2008). Serta hasil penelitian Nanny Dyah Zelianti mendapatkan hasil $p$ value 0,000 bahwa ada perbedaan sebelum dan sesudah diberikan terapi relaksasi nafas dalam.

Selain itu didukung oleh teori Smaltzer \& Bareyang menyatakan bahwa relaksasi nafas dalam dapat meningkatkan ventilasi alveoli, memelihara pertukaran gas, mencegah atelektasi paru, memberikan perasaan tenang, mengurangi stress baik stress fisik maupun emosional (Sumirta, 2013). Menurut Widyastuti terapi relaksasi nafas dalam tidak hanya menyebabkan efek yang menenangkan fisik tetapi juga menenangkan pikiran (Nanny, 2010).

Pada pasien perilaku kekerasan, terapi relaksasi nafas dalam dapat merangsang tubuh untuk melepaskan opioid endogen yaitu endorphin dan enkefalin. Dilepaskannya hormone endorphin dapat memperkuat daya tahan tubuh, menjaga sel otak tetap muda, melawan penuaan, menurunkan agresifitas dalam hubungan antar manusia, meningkatkan semangat, daya tahan, dan kreatifitas (Sumirta, 2013). Terapi relaksasi nafas dalam tidak saja menyebabkan efek yang menenangkan fisik tetapi juga menenangkan pikiran. Oleh karena itu beberapa terapi relaksasi seperti nafas dalam dapat membantu untuk meningkatkan kemampuan berkonsentrasi, kemampuan mengontrol diri, menurunkan emosi, dan depresi (Yuhanda, 2013).

Ditinjau dengan data umum pada pasien perilaku kekerasan sesudah diberikan terapi relaksasi nafas dalam terjadi penurunan perilaku kekerasan. Dengan ini untuk mencegah perilaku kekerasan berulang sebaiknya dilakukan terapi relaksasi nafas dalam selama 3 kali dalam seminggu tidak lebih dari 2 hari berturut-turut melakukan relaksasi nafas dalam dan dilakukan selama 2-4 minggu. Setelah penelitian ini responden dapat melakukan terapi tersebut dengan sendiri karena responden sudah mengetahui reaksi terapi relaksasi nafas dalam dan dapat merasakan bagaimana perubahannya sesudah melakukan terapi relaksasi nafas dalam, responden merasakan lebih tenang dan dapat mengurangi stress dan emosi yang tidak terkontrol.

Dengan ini sudah terbukti bahwa sesudah diberikan terapi relaksasi nafas dalam dapat mengurangi perilaku kekerasan, karena relaksasi nafas dalam dapat mengurangi stress maupun emosi serta memberikan perasaan tenang dan mampu mengontrol diri. Maka terapi relaksasi nafas dalam bermanfaat untuk pasien perilaku kekerasan. Hal ini menunjukkan bahwa ada perbedaan perilaku kekerasan sebelum dan sesudah terapi relaksasi nafas dalam pada pasien perilaku kekerasan di Ruang Kenari Rumah Sakit Jiwa Menur Surabaya.

\section{KESIMPULAN}

Berdasarkan penelitian yang telah dilakukan dapat ditarik kesimpulan sebagai berikut :

1. Perilaku kekerasan sebelum diberikan terapi relaksasi nafas dalam pada pasien perilaku kekerasan di Ruang Kenari Rumah 
Sakit Jiwa Menur Surabaya berada pada kategori sedang sebanyak 24 pasien (80\%).

2. Perilaku kekerasan sesudah diberikan terapi relaksasi nafas dalam pada pasien perilaku kekerasan di Ruang Kenari Rumah Sakit Jiwa Menur Surabaya berada pada kategori ringan sebanyak 25 pasien (83,3\%).

3. Ada perbedaan intensif perilaku kekerasan sebelum dan sesudah terapi relaksasi nafas dalam pada pasien perilaku kekerasan di Ruang Kenari Rumah Sakit Jiwa Menur Surabaya.

\section{SARAN}

Penelitian ini dapat memberikan pengetahuan dan dapat memanfaatkan metode yang ada bagi responden khususnya, pada masyarakat umum dalam menurunkan perilaku kekerasan pada pasien perilaku kekerasan.

\section{DAFTAR PUSTAKA}

Dewi, D, dkk. (2009). Jurnal. Pengaruh Teknik Relaksasi Napas Dalam terhadap Penurunan Persepsi Nyeri pada Lansia dengan Artritis Reumatoid. http://jos.unsoed.ac.id/index.php/kepera watan/article/view/179

Hamid, A.Y. (2008). Bunga Rampai Asuhan Keperawatan Kesehatan Jiwa.Jakarta:EGC

Kustanti, E \& Widodo, A. (2008). Jurnal. Pengaruh Teknik Relaksasi Terhadap Perubahahan Status Mental Skizofrenia di Rumah Sakit Jiwa Surakarta. https://publikasiilmiah.ums.ac.id/handle /11617/498

Kusumawati F dan Hartono, Y. (2010). Buku Ajar Keperawatan Jiwa. Jakarta : Salemba Medika Kelliat, B.A. (2012). Keperawatan Kesehatan Jiwa. Jakarta: EGC

Nanny \& Sujarwo. (2010). Jurnal. Pengaruh Teknik Relaksasi Nafas Dalam Terhadap Tingkat Emosi Klien Perilaku Kekerasan di Rumah Sakit Jiwa Daerah Dr. Amino Gondohutomo Semarang.
Nursalam. (2013). Metode Penelitian Ilmu Keperawatan : Pendekatan Praktis. Jakarta : Salemba Medika.

Sumirta, N, dkk. (2013). Jurnal. Relaksasi Nafas Dalam Terhadap Pengendalian Marah Klien Dengan Perilaku Kekerasan. http://poltekkesdenpasar.ac.id/files/J URNAL\%20GEMA\%20KEPERA WATAN/JUNI\%202014/Nengah\%2 OSumirta, \%20dkk.pdf

Videbeck, S. (2008). Buku Ajar Keperawatan Jiwa.Jakarta:EGC

Yosep, I. (2010). Keperawatan Jiwa (Edisi Revisi). Bandung : Refika Aditama.

Yuhanda, D, dkk. (2013).Jurnal. Efektivitas terapi relaksasi nafas dalam dan tertawa dalam mengontrol perilaku kekerasan pada pasien perilaku kekerasan di RSJD Dr.Amino Gondo Hutomo Semarang. 
